\title{
Synthesis of Acrylonitrile Based High Internal Phase Emulsion Monoliths and their Application in Recovery of Heavy Metal Ions
}

Abdul Wasif Shaikh*, Sarika Deokar, Khudbudin Mulani, Nayaku Chavan, Chelanattu Raman Rajan, Surendra Ponrathnam

Polymer Science and Engineering Division, CSIR-National Chemical Laboratory, Pune, India

\section{A R T I C L E I N F O}

Received: 28 April 2019

Revised: 11 June 2019

Accepted: 26 June 2019

Available online: 29 June 2019

DOI: $10.33945 /$ SAMI/AJCA.2020.1.5

\section{K E Y W O R D S}

\section{PolyHIPEs}

Amidoxime

Chromium (VI)

Adsorption isotherms

\section{A B S T R A C T}

Polymeric monoliths based on acrylonitrile-divinyl benzene were synthesized successfully by high internal phase emulsion (HIPE) polymerization. Highly porous polyHIPEs were prepared by variation in oil to water ratio as well as type and concentration of porogens. The porogens evaluated were toluene, chlorobenzene, heptane and chloroform. The effect of oil to water ratio and porogen type and concentrations on morphology and surface area of polyHIPEs were investigated. The polyHIPEs were modified to amidoxime functionality by treating base catalyzed reaction with hydroxylamine hydrochloride in presence of base. The treated and modified polymeric monoliths were characterized by FT-IR, SEM and surface area analysis. The modified porous polyHIPEs were tested for adsorption of $\mathrm{Cr}(\mathrm{VI})$ metal ions at various $\mathrm{pH}$.

GR A P H I C A L A B S T RACT

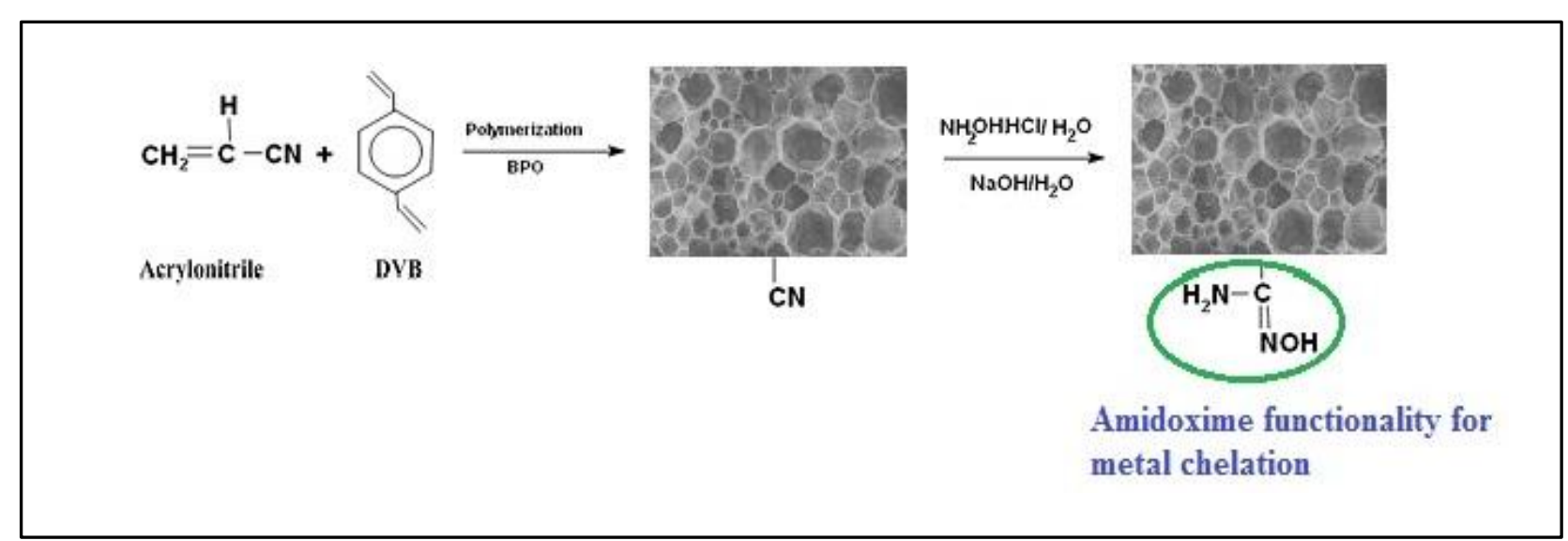

* Corresponding author's E-mail address: abdulwshaikh16@gmail.com 


\section{Introduction}

High internal phase emulsion is a concentrated emulsion in which the discontinuous phase occupies more than or equal to $74 \%$ of volume of the total emulsion [1]. The discontinuous phase is replaced by voids or pores leading to highly porous structure. Lissant described the structure and properties of the non-Newtonian, thixotropic Bingham fluids termed as high internal phase emulsions (or high internal phase ratio emulsions, HIPREs) [2-4]. These emulsions have also been referred to as concentrated emulsions [5-7], gel emulsions [8-10], and hydrocarbon gels [11]. The resulting porous polymers formed have three dimensional porous structure with formation of cells of different morphologies [12-14]. The morphological features such as cell size,interconnecting pore size and porosity can be efficiently controlled.These polyHIPEs can be used as scaffolds [15], nanocomposites[16], magnetic polyHIPEs [17], solid-phase peptide synthesis[18] and chromatographic applications[19,20].

Recently, adsorption is more efficient technology for decontamination of waste water. Adsorption with reagent impregnated resins and a metal-bonded chelating resin has become increasingly popular during last two decades [21,22]. The number of polymers containing chelating group have been prepared using various starting materialas and applied for adsorption of different metals [23-25]. Crosslinked porous polymers of acrylonitrile (AN) and divinylbenzene (DVB), are interesting products that are used as sorbents and stationary phases for gas chromatography [26]. The advantage of ANDVB polyHIPE monoliths over the conventional beaded copolymers is to have uniform interconnected porous structure with high surface areas that can be prepared in any desired forms and shapes [27]. The reactive pendant nitrile group on the polymer backbone can be modified to amidoxime by reacting it with hydroxylamine, hydrazine group by nucleophilic addition and cycloaddition reactions. Amidoxime group forms stable complexes with different metal ions [28-30]. Consequently, the polymers with the amidoxime groups can be successfully used for the preconcentration of trace metals from aqueous solutions.

Chromium bearing waste water originates from a variety of industrial processes such as electroplating, dichromate, basic chrome sulphate manufacturing, tannery, anodizing, cutting tools, chrome mining etc. Many of these industrial processes usually produce a large volume of waste-water with a chromium concentration ranging from less than $1 \mathrm{ppm}$ to $10 \mathrm{ppm}$. The $\mathrm{Cr}(\mathrm{VI})$ is approximately 100 times more toxic than $\mathrm{Cr}$ (III) [31]. In view of the toxic nature of $\mathrm{Cr}(\mathrm{VI})$, development of methods in order to establish their levels in the environment and industrial quality control are quite significant. Solid phase extraction has been explored for the preconcentration of many metal ions [32-35]. A variety of adsorbents have been used for the preconcentration of chromium, but they are relatively expensive [36]. Therefore it is interesting to investigate the possibility of porous polyHIPE monoliths having amidoxime groups on the surface for adsorption and desorption of metal ions. Present work deals with preparation of acrylonitrile-DVB porous polymeric monoliths having comparatively higher surface area. Further these polyHIPEs were subjected to post modification reactions to convert the nitrile functionality to amide functionality followed by converting it to amidoxime functionality. The amidoxime modified monoliths were then tested for its efficiency as heterogeneous supports for the adsorption of $\mathrm{Cr}(\mathrm{VI})$ metal ion. The structure and properties of polymers are characterized by FTIR, SEM and surface area. 


\section{Experimental}

\section{Materials and methods}

Acrylonitrile (AN), Sorbitan monooleate (Span 80),sodium peroxydisulphate (NaPS), ascorbic acid (ASA), hydroxylamine hydrochloride and potassium dichromate procured from Loba Chemie, India. Acetone, heptane, toluene, chlorobenzene, chloroform, sulfuric acid-98\% and nitric acid-70\% are purchased from Merck India. Divinylbenzene (DVB) $80 \%$ and 1,5-Diphenylcarbazide (DPC) from Sigma Aldrich, USA and were used as received. Chromium (VI) stock solution (35.2 $\mathrm{mg} / \mathrm{L}$ ) was prepared by dissolving accurately weighed potassium dichromate in $100 \mathrm{~mL}$ with deionized water. $0.025 \mathrm{wt} \%$ solution of DPC was prepared by dissolving $25 \mathrm{mg}$ of DPC in $5 \mathrm{~mL}$ of acetone and $10 \mathrm{~mL}$ of $5 \mathrm{M}$ sulfuric acid and subsequently diluted to $100 \mathrm{~mL}$ with deionized water. The solution was kept in an amber coloured glass bottle. Water was deionized and purified with a Milli-Q water purification system (Millipore, USA). Freshly prepared solutions were used for all experiments.

\section{Procedure for synthesis of AN-DVB polyHIPEs}

The monomer composition is shown in Table 1.The oil phase comprising of requisite amounts of acrylonitrile (2.546g), divinylbenzene (6.247g), span 80 (1.758g) and porogen was taken in a $100 \mathrm{~mL}$ plastic container. The deionized water in $\mathrm{w} / \mathrm{o}$ ratios (1:10/20, oil: water) as a discontinuous phase was added drop-wise to the oil phase under constant stirring (1400 rotations per minute) at room temperature. The HIPE was formed slowly and the addition was continued at the same rate until total water was incorporated. After complete addition of water, the redox initiating system consists of sodium persulphate: ascorbic acid(1:0.5) dissolved in $1 \mathrm{~mL}$ water and added to the reactor under stirring $(2 \mathrm{~mL}$ water is the inclusive of total water used). Then HIPE formed was polymerized at $50^{\circ} \mathrm{C}$ in constant temperature water bath. The polymerization was continued for a period of $8 \mathrm{~h}$ to ensure complete polymerization. The monoliths obtained after polymerization were then subjected to soxhlet extraction using methanol for $12 \mathrm{~h}$, followed by drying at room temperature. The monoliths were then subsequently characterized for surface area and morphology.

\section{Chemical modification of AN-DVB polyHIPEs}

The reaction for the modification of ANDVB polymers is schematically represented in Figure 1. AN-DVB polyHIPE (1.5 g) was taken in a $100 \mathrm{~mL}$ round bottom flask equipped with a water condenser. To the flask $2.0 \mathrm{~g}$ of hydroxylamine hydrochloride dissolved in 30 mL of methanol: water $(5: 1) \mathrm{v} / \mathrm{v}$ was added. To the above reaction mixture, $0.1 \mathrm{M}$ sodium hydroxide solution was added to neutralize hydrochloric acid in hydroxyl amine hydrochloride and then reflux the reaction mixture over a period of $24 \mathrm{~h}$. The modified polymer was then filtered off and washed thoroughly with water followed by methanol and finally dried in oven at $60^{\circ} \mathrm{C}$ for $8 \mathrm{~h}$.

\section{Post polymerization characterization}

FTIR spectra of polymers were recorded on FTIR (PerkinElmer) spectrophotometer. The samples were prepared after drying the polymer at $80^{\circ} \mathrm{C}$ for $3 \mathrm{~h}$. The potassium (KBr) pellets were prepared by mixing $1 \mathrm{mg}$ of sample with $100 \mathrm{mg}$ of $\mathrm{KBr}$. The spectra were recorded from 4000-450 $\mathrm{cm}^{-1}$ (8 scans). Surface morphologies of the polyHIPE prepared were studied using Lieca Stereoscan 440 Scanning Eelectron Microscope (SEM) at different magnifications. The energy of analysis was $20 \mathrm{keV}$. Surface area analysis of porous polyHIPEs were determined using NOVA 2000e surface area analyzer (Quantachrome, USA). The analysis was done 
using pure nitrogen at a flow rate of 10 psi. The samples were degassed for $3 \mathrm{~h}$ at $60{ }^{\circ} \mathrm{C}$ prior to analysis. The obtained data was processed by an Autosorb 1 software using Brunauer-Emmett-Teller (BET) method.

\section{Adsorption of $\operatorname{Cr}(V I)$}

Batch method was used to investigate the adsorption study of $\mathrm{Cr}(\mathrm{VI})$ on AN-DVB polyHIPEs. For the determination of the effect of $\mathrm{pH}$ on $\mathrm{Cr}(\mathrm{VI})$ sorption, $100 \mathrm{mg}$ of resin was immersed into $10 \mathrm{~mL}$ (35.2 ppm) Cr(VI) stock solution at different $\mathrm{pH}$. The mixture was stirred at room temperature for $24 \mathrm{~h}$. The concentration of $\mathrm{Cr}(\mathrm{VI})$ ions in the effluent was determined spectrophotometrically using a UV spectrophotometer (Shimadzu, Japan) by development of a purple color with 1, 5-diphenyl carbazide in acidic solution as complexing agent. Absorbance of the purple colored solution was observed at $\lambda=540 \mathrm{~nm}$ after 20 min against blank. Based on the optimum conditions, Beer's law holds well in the concentration range $0.08-0.51 \mathrm{mg} / \mathrm{mL}$ and the regression equation is $y=4.307 x$ with a correlation coefficient of 0.997 .

\section{Results and discussion}

Evalution of porogen

PolyHIPEs of AN-DVB were synthesized with variation in different parameters such as oil to water ratio, type and concentration of porogens. Four different porogens employed in the polyHIPE preparation were heptane, toluene, chlorobenzene and chloroform. The effect of these porogens and their concentration on the surface area and pore volume of the polymers are shown in Table 1. The porogen is refered as pore forming agents. It is chemically inert and can be easily removed from reaction mixture resulting in formation of porous polymeric material. The porogen is an important parameter in respect to polymer surface area.

The results show that the use of different types of porogen led to considerable increase in surface area. It was also observed that toluene acts as good solvent for monomer as well as polymer, this leads to produce polymer having higher surface area. In case where heptane (ADP 01) was used as porogen, the surface area obtained was 162 $\mathrm{m}^{2} / \mathrm{g}$ for 1:0.5 ratio of oil to porogen for system having a monomer phase oil to water ratio of 1:10. In case of toluene (ADP 02) as porogen, the corresponding surface area was $101 \mathrm{~m}^{2} / \mathrm{g}$. On the other hand, where chlorinated solvents i.e. chlorobenzene (ADP 03) and chloroform (ADP 04) were used as porogen, the surface area were 108 and 56 $\mathrm{m}^{2} / \mathrm{g}$ respectively.

Table 1. Monomer composition (cross link density 100\%)

\begin{tabular}{|c|c|c|c|c|c|c|c|c|}
\hline $\begin{array}{l}\text { Polymer } \\
\text { code }\end{array}$ & $\begin{array}{c}\mathrm{ACN} \\
(\mathrm{g})\end{array}$ & $\begin{array}{l}\text { DVB } \\
\text { (g) }\end{array}$ & $\begin{array}{l}\text { Span } \\
80\end{array}$ & $\begin{array}{l}\mathrm{O}: \mathrm{W} \\
\text { ratio }\end{array}$ & $\begin{array}{l}\text { Porogen } \\
\text { in } m L\end{array}$ & $\begin{array}{l}\text { Porogen } \\
\text { ration }\end{array}$ & $\begin{array}{c}\text { Surface } \\
\text { area } \\
\left(\mathrm{m}^{2} / \mathrm{g}\right)\end{array}$ & $\begin{array}{c}\text { Pore } \\
\text { volume } \\
\left(\mathrm{cm}^{3} / \mathrm{g}\right)\end{array}$ \\
\hline ADP 01 & & & & $1: 10$ & Heptane (7.7) & $1: 0.5$ & 162.07 & 0.058 \\
\hline ADP 02 & & & & $1: 10$ & Toluene (6.1) & $1: 0.5$ & 101.77 & 0.037 \\
\hline ADP 03 & 2.546 & 6.247 & 1.758 & $1: 10$ & $\begin{array}{l}\text { Chlorobenzene } \\
\qquad(4.8)\end{array}$ & $1: 0.5$ & 108.37 & 0.038 \\
\hline ADP 04 & & & & $1: 10$ & Chloroform (3.6) & $1: 0.5$ & 56.28 & 0.020 \\
\hline ADP 05 & & & & $1: 20$ & Toluene (12.2) & $1: 1$ & 329.74 & 0.013 \\
\hline ADP 06 & & & & $1: 20$ & Toluene (6.1) & $1: 0.5$ & 206.75 & 0.070 \\
\hline
\end{tabular}


Figure 1. Chemical modification of ANDVB polyHIPEs

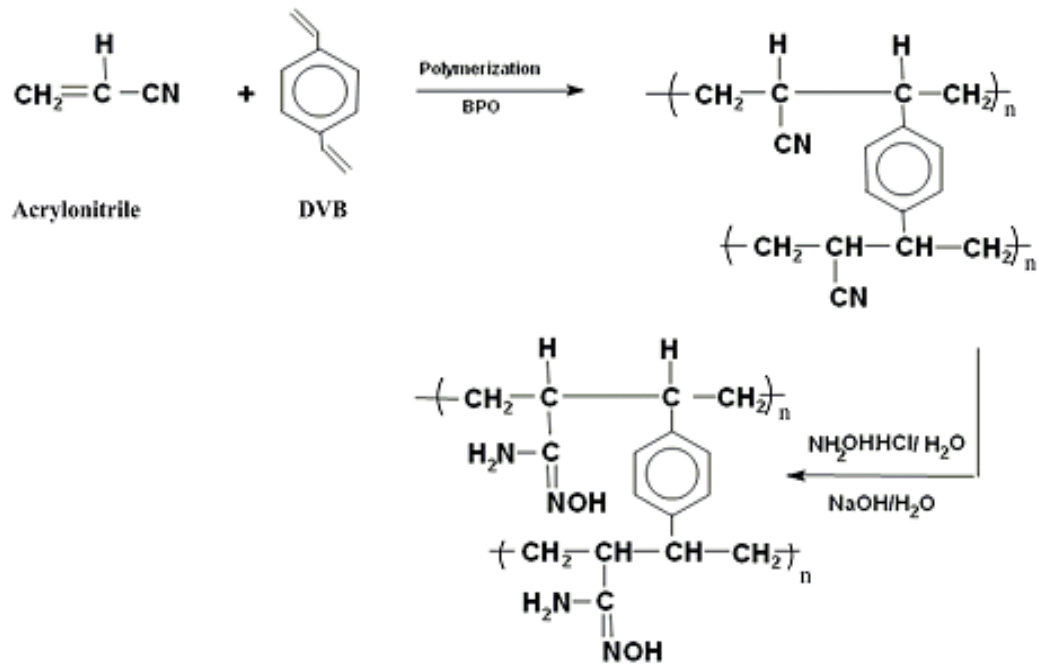

Heptane acts as a non solvent for the polymer while toluene acts as a solvent for the polymer. Hence the phase separation period of the polymer during polymerization is responsible for forming micropores or macropores reflecting in the surface area data. However, the polyHIPEs synthesized using toluene (ADP 05) as porogen with oil to porogen ratio of $1: 1$ and having an monomer phase oil to water ratio of $1: 10$, the maximum surface area of $329.74 \mathrm{~m}^{2} / \mathrm{g}$ was achieved. Surface area of $206.75 \mathrm{~m}^{2} / \mathrm{g}$ was observed for polyHIPEs (ADP 06) prepared with oil to toluene ratio of 1:0.5. It was also found that by increasing the oil:water ratio, the increase in the surface area and the adsorption capacity of $\mathrm{Cr}(\mathrm{VI})$ were increased significantly.

\section{SEM analysis}

Scanning electron microscopy (SEM) is an important tool for studying the surface morphology of polymer. Scanning electron micrographs of the AN-DVB polyHIPEs synthesized using different porogens consisting of 1:10 and 1:20 oil: water ratios are shown in Figures 2 to 3. While preparing monolithic polymers, two parameters were paid attention to, one is stability of emulsion and other is morphology of monolithic polymers in respect of pore volume and pore size. The emulsions are thermodynamically unstable. The stability of emulsions was attained by using low HLB surfactant around 4 viz. Span 80 . On the other hand, morphology of emulsion is influenced by water to oil phase ratio. In this study, a series of monolithic polymers were preapered by varying oil to water ratio and the respective SEM images are shown in Figure 2 and 3.

As seen in the Figure 2 and 3 and Table 1, monoliths with lower pore volume and smaller voids were obtained. Addition of porogen in HIPE leads to increase in viod diameter [1]. HIPE prepared by using heptane (ADP 01 ) as a porogen $(0.5 \%)$, pore volume of polymers was $0.058 \mathrm{~cm}^{3} / \mathrm{g}$. The pore volume of HIPE polymer prepared by using chlorobenzene (ADP 03) and chloroform (ADP 04) were 0.038 and $0.020 \mathrm{~cm}^{3} / \mathrm{g}$ respectively. However, $0.037 \mathrm{~cm}^{3} / \mathrm{g}$ pore volume was found when toluene (ADP 02) is used as porogen. When volume of aqueous phase increases, pore volume also increases. In case of toluene as a porogen, surface area and pore volume of HIPE polymers (ADP 05 and ADP 06) are $206 \mathrm{~m}^{2} / \mathrm{g}$ and $0.070 \mathrm{~cm}^{3} / \mathrm{g}$ respectively. The micropore polymer have a tendency to have high adsorption capacity because they have higher surface area. The high adsorption capacity of monolith ADP 05 

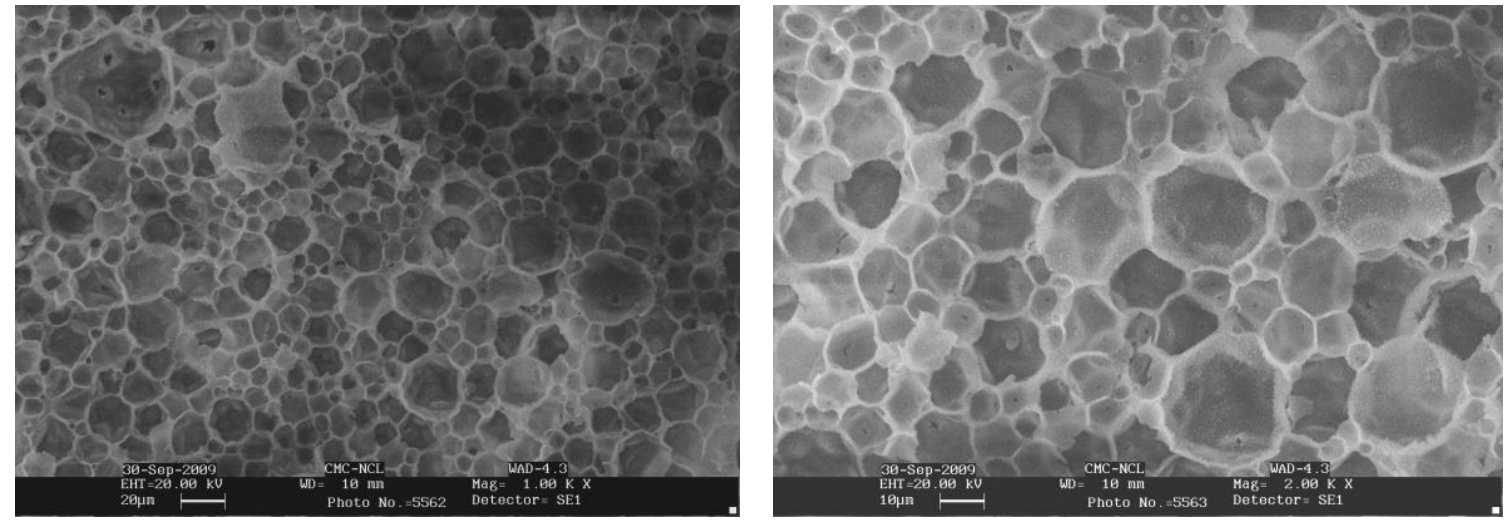

Figure 2. SEM images of AN-DVB polyHIPEs obtained using 1:10 (oil: water) ratio with toluene as porogen in 1:1 (monomer phase: toluene) ratio
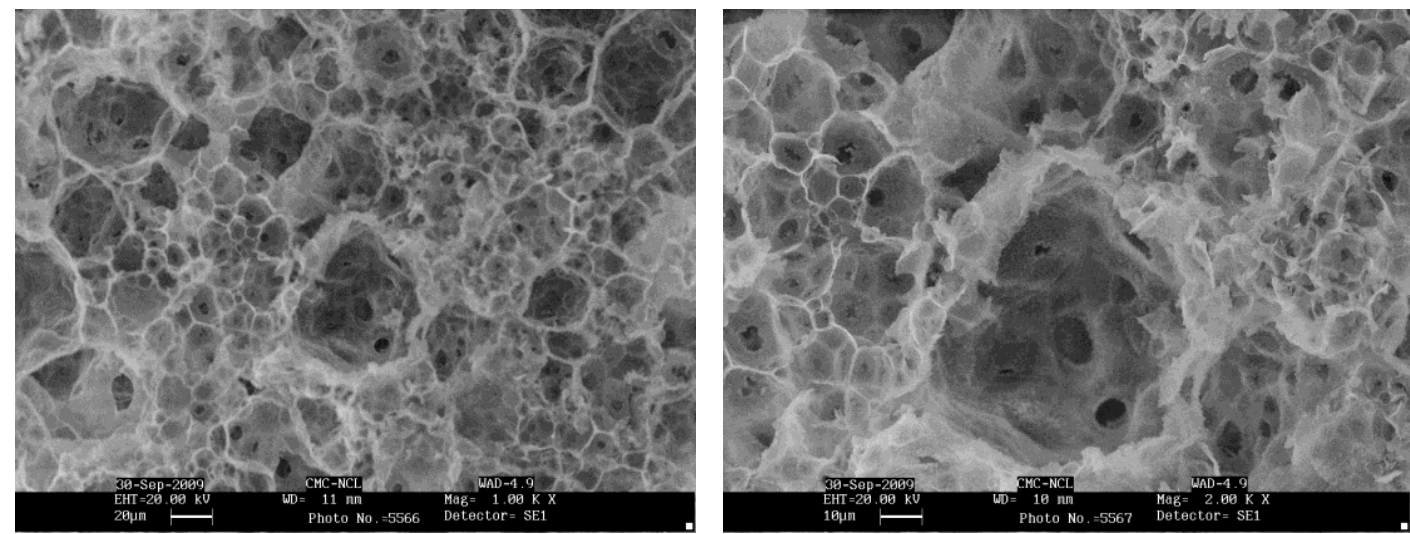

Figure 3. SEM images of AN-DVB polyHIPEs obtained using 1:20 (oil: water) ratio with toluene as porogen in 1:1 (monomer phase: toluene) ratio

is attributed to the close cell structure of polymer that not only increased surface area but also provide greater active sites for metal chelation. On the other hand, monoliths ADP 04 having lower surface area had lower adsorption capacity may be due to lesser available active sites.

\section{FT-IR spectroscopy}

The FT-IR spectroscopy is an very powerful technique to identify and verify certain functional groups in compound under modification. The unmodified and amidoxime modified AN-DVB monoliths were characterized by infrared spectroscopy to confirm the modification of nitrile group to amidoxime group. The peak at $1702 \mathrm{~cm}^{-1}$ attributed to the $\mathrm{C}=0$ group disappears in spectrum of modified polymer. The peak at $2239 \mathrm{~cm}^{-1}$ corrosponds to $-\mathrm{C} \equiv \mathrm{N}$ stretching vibrations, which is the characteristic peak of the nitrile functionality. In the amidoxime modified polymer, the main characteristic absorption peaks observed at $1658 \mathrm{~cm}^{-1}, 1607$ and $900-950 \mathrm{~cm}^{-1}$ are due to $-\mathrm{C}=\mathrm{N},-\mathrm{NH}_{2}$, and $=\mathrm{N}-\mathrm{O}-$ groups respectively. When comparing the spectrum of modified polymer with unmodified polymer, the absortion band around $3350-3650 \mathrm{~cm}^{-1}$ indicating the presence of $-\mathrm{OH}$ group that belongs to the amodoxime group. The spectrum also shows presence of peak at $2239 \mathrm{~cm}^{-1} \quad(-\mathrm{C} \equiv \mathrm{N}$ 
stretching) due to incomplete modification. This was because the polyHIPEs formed has some closed pores and hence all the functional groups present within the polyHIPE monolithic matrix may not be accessible for modifications. The diffusion of the reactants in to the porous matrices for modification becomes difficult.

\section{Effect of $p H$}

Figure 4 represents the comparison of percentage adsorption of $\mathrm{Cr}(\mathrm{VI})$ at different $\mathrm{pH}$ for the polymers synthesized with variation in porogen type having a ratio of 1:0.5 (monomer phase: porogen ratio) and 1: 10 (oil: water ratio). Adsorption studies of $\mathrm{Cr}(\mathrm{VI})$ were studied in the $\mathrm{pH}$ range of 2-8. The experimental results revealed that the $\mathrm{Cr}(\mathrm{VI})$ adsorption on the polymer was high (99.8\%) at low $\mathrm{pH}(\mathrm{pH}=2) . \mathrm{Cr}(\mathrm{VI})$ exists in aqueous phase in different anionic forms such as chromate $\left(\mathrm{CrO}_{4}^{2-}\right)$, dichromate $\left(\mathrm{Cr}_{2} \mathrm{O}_{7}{ }^{2-}\right)$, or hydrogen chromate $\left(\mathrm{HCrO}_{4}{ }^{-}\right)$. The dominant form of $\mathrm{Cr}(\mathrm{VI})$ at lower $\mathrm{pH}$ is $\mathrm{HCrO}_{4}^{-}$. Increasing the $\mathrm{pH}$ shifts the concentration of $\mathrm{HCrO}_{4}$ - to other forms as $\mathrm{CrO}_{4}{ }^{2-}$ and $\mathrm{Cr}_{2} \mathrm{O}_{7}{ }^{2-}$.

The polyHIPEs synthesized using different porogens and their ratios were evaluated for its adsorption efficiency at different $\mathrm{pH}$. The porogens used were toluene, heptane, chloroform and chlorobenzene. In all the polyHIPEs maximum adsorption of $\mathrm{Cr}(\mathrm{VI})$ was observed at pH-2. In case of heptane (ADP 01) , toluene (ADP 02) and chloroform(ADP 04) used as porogens, the percentage $\mathrm{Cr}(\mathrm{VI})$ adsorption was 91.6, 99.8 and 91.5 respectively, while in case of chlorobenzene (ADP 03) the adsorption was comparatively less i.e. up to $66.8 \%$. The adsorption efficiency was found to decrease with increase in $\mathrm{pH}$. At $\mathrm{pH}-3$, the percentage $\mathrm{Cr}(\mathrm{VI})$ adsorption was 51.3, 79.6 and 35.42 for heptane (ADP 01), toluene (ADP 02) and chloroform (ADP 04) respectively while AN-DVB polyHIPEs synthesized using chlorobenzene (ADP 03) showed poor adsorption efficiency of $22.2 \%$.
At pH 4, 6 and 8 heptane (ADP 01) showed steady adsorption efficiency of approximately $31 \%$. The same trend was observed in case of chlorobenzene (ADP 03) and chloroform (ADP 04) having an approximate value of $20 \%$. But in case of toluene (ADP 02) at same conditions, the percentage $\mathrm{Cr}(\mathrm{VI})$ adsorption values were, 57.4, 43.1 and 31.8 respectively. AN-DVB polyHIPEs synthesized using toluene (ADP 02) as a porogen, had maximum adsorption efficiency as compared to chlorobenzene. Porogens play an important role in deciding the surface area, pore dimensions and morphology. Therefore their effect was reflected in the adsorption behaviour studies.

Figure 5 depicts a comparison of AN-DVB polyHIPEs evaluated for $\mathrm{Cr}(\mathrm{VI})$ adsorption at different $\mathrm{pH}$ synthesized using 1:0.5 and 1:1 (monomer phase: toluene) ratio with monomer phase comprising of 1:20 (oil: water) ratio. The effect of monomer phase: toluene ratio on the adsorption was studied. There was no conditions.

The decrease in the adsorption with increase in $\mathrm{pH}$ may be due to the decrease in electrostatic force of attraction between sorbent and sorbate ions. At lower $\mathrm{pH}$, the percentage of $\mathrm{Cr}(\mathrm{VI})$ removal is high due to the high electrostatic force of attraction.

The decrease in adsorption above $\mathrm{pH}-4$ may also be due to occupation of the adsorption sites by anionic species like $\mathrm{CrO}_{4}{ }^{2-}$ and $\mathrm{Cr}_{2} \mathrm{O}_{7^{2}}$, which retards the adsorption of such ions further towards the adsorbent surface. As the $\mathrm{pH}$ increases, the overall surface of amidoxime polymers became negative and thus adsorption decreases.

\section{Effect of contact time}

Based on the adsorption data in above section, the polymer synthesized with 1:0.5 (oil: toluene) ratio with monomer phase comprising of 1:10 (oil: water) showed maximum adsorption and hence was selected 
Figure 4. Effect of $\mathrm{pH}$ on

Cr(VI) adsorption on AN-

DVB polyHIPEs using

different porogens
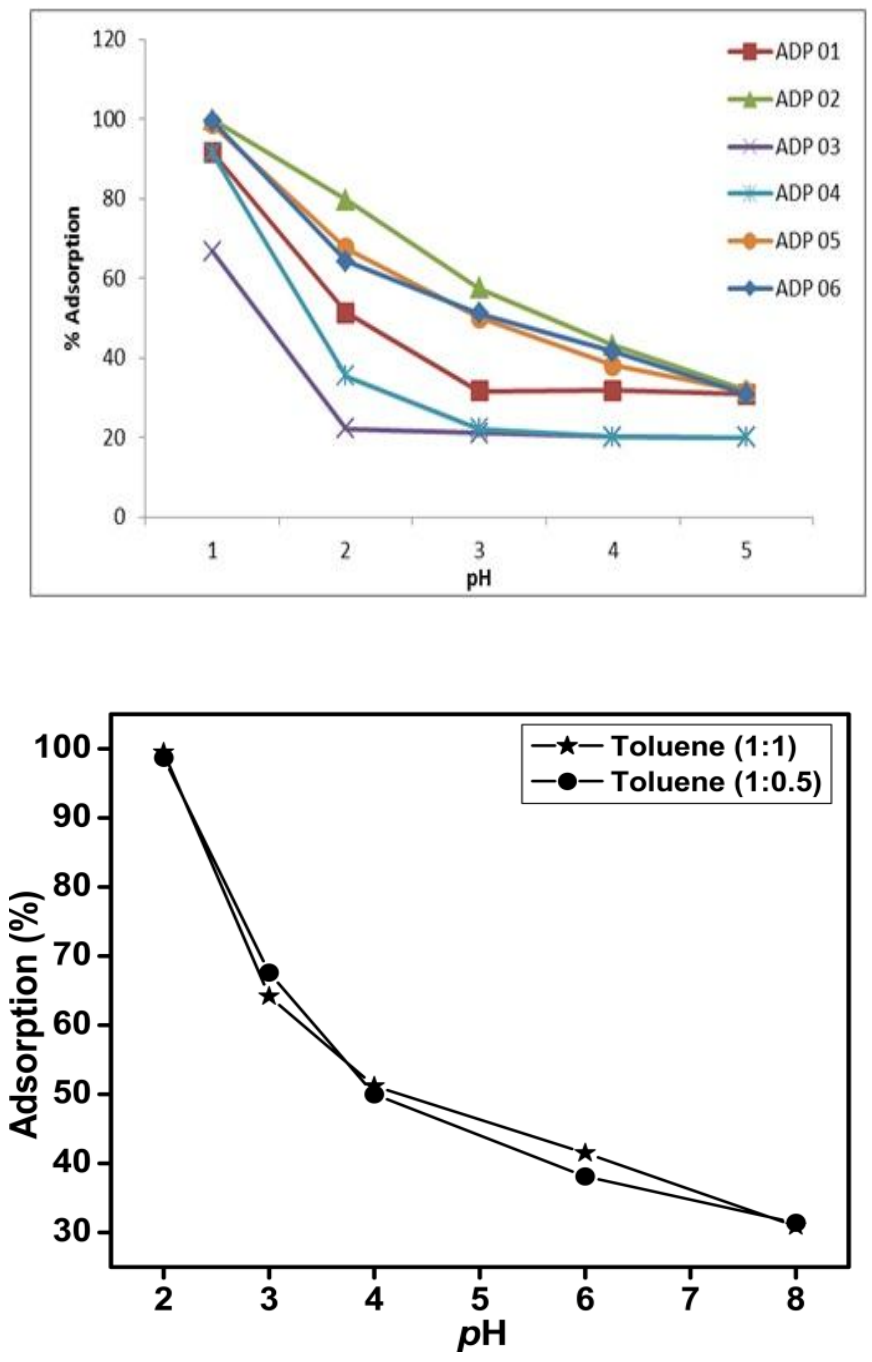

Figure 5. Effect of $\mathrm{pH}$ on $\mathrm{Cr}(\mathrm{VI})$ adsorption on AN-DVB polyHIPEs using different porogen ratios at 1:20; oil: water ratio equilibrium is achieved diffusion of the $\mathrm{Cr}(\mathrm{VI})$ solution on the polymer matrix is difficult since all the accessible sites and pores are being used off. The mechanism of solute transfer to the solid includes diffusion through the fluid film around the adsorbent particle and pores to the internal adsorption sites. Initially the concentration gradient between the film and the solid surface is high and hence the transfer of solute onto the solid surface is faster. Therefore the optimum time for adsorption of $\mathrm{Cr}(\mathrm{VI})$ on modified polymer was chosen as $150 \mathrm{~min}$, for all batch studies.

\section{Effect of Cr(VI) concentration}

Adsorption efficiency of $\mathrm{Cr}(\mathrm{VI})$ is dependent on the concentration of $\mathrm{Cr}(\mathrm{VI})$ in 
aqueous solutions. The relative adsorption of $\mathrm{Cr}(\mathrm{VI})$ with respect to the amount of $\mathrm{Cr}(\mathrm{VI})$ in solution was studied. The $\mathrm{Cr}(\mathrm{VI})$ concentration was varied from 50 to $200 \mathrm{ppm}$. The effect of initial concentration on percentage removal of $\mathrm{Cr}(\mathrm{VI})$ is depicted in Figure 7. The percentage removal of $\mathrm{Cr}(\mathrm{VI})$ increases with increase in initial $\mathrm{Cr}(\mathrm{VI})$ concentration. It may be due to an increase in the number of $\mathrm{Cr}(\mathrm{VI})$ ions for the fixed amount of adsorbent and the rate of adsorption is high due to the maximum amidoxime functional groups accessible. Due to adsorption, a thick layer was formed and thus the capacity of the adsorbent gets exhausted resulting in control of uptake rate by the sorbate which is transported from the exterior to the interior sites of the adsorbent particles. The results indicate that the initial $\mathrm{Cr}(\mathrm{VI})$ ion concentration determines the equilibrium concentration and hence the uptake rate of $\mathrm{Cr}(\mathrm{VI})$ ion and the kinetic characteristics.

\section{Effect of adsorbent dose}

The effect of amount of polymer on adsorption capacity was studied. The modified polymer was taken at various amounts (50 to $250 \mathrm{mg}$ ) and was mixed with the metal ion solution and kept at room temperature for $24 \mathrm{~h}$. The adsorption capacities of polymer at different amounts were determined by keeping all other factors constant, such as $\mathrm{pH}$ and temperature. The percentage $\mathrm{Cr}(\mathrm{VI})$ adsorption at different polymer quantity is shown in Figure 8. It was observed that percent removal of $\mathrm{Cr}(\mathrm{VI})$ increases with increase in weight of polymer due to the greater availability of functional groups present for binding with an increase in concentration of adsorbent. If the adsorbent amount is increased by keeping the $\mathrm{Cr}(\mathrm{VI})$ concentration constant, the amount of $\mathrm{Cr}(\mathrm{VI})$ adsorbed per unit mass decreased due to availability of lower number of $\mathrm{Cr}(\mathrm{VI})$ ions per unit mass of adsorbent. For $35.2 \mathrm{ppm}$ of $\mathrm{Cr}(\mathrm{VI})$ concentration at $\mathrm{pH} \mathrm{2,} \mathrm{optimum} \mathrm{values} \mathrm{of}$ percentage adsorption and adsorbent amount were $98 \%$ and $250 \mathrm{mg}$ respectively.

\section{Adsorption kinetics}

To evaluate sorption dynamics, it requires consideration of two important physicochemical parameters such as kinetics and equilibrium of adsorption. Adsorption isotherms of $\mathrm{Cr}(\mathrm{VI})$ were investigated at the optimum $\mathrm{pH}$ 2. The kinetics describes the solute up-take rate which in turn governs the contact time. The equilibrium study deals with determination of the distribution of solute between solid-liquid phases and determining feasibility and capacity of the sorbent for adsorption.

Figure 6. Effect of contact time on $\mathrm{Cr}(\mathrm{VI})$ adsorption

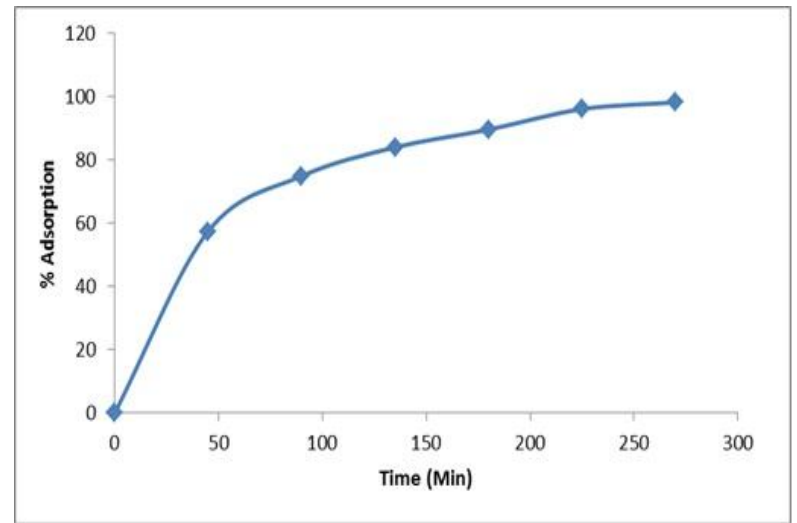


Figure 7. Effect of $\mathrm{Cr}(\mathrm{VI})$ loading on adsorption

Figure 8. Effect of polymer dose on Cr(VI) adsorption
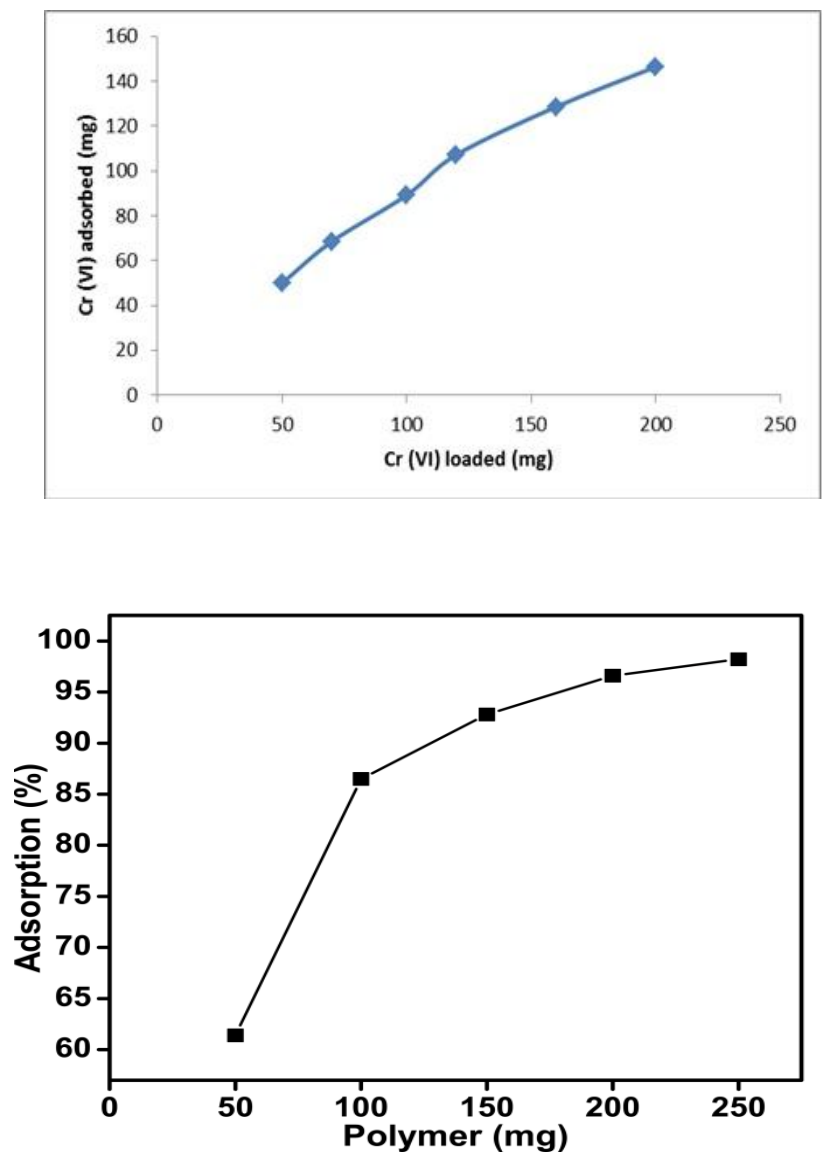

Kinetic models widely used to explain the mechanism of adsorption in progress are as shown by equation (1) and (2) [37,38]. The equations (1) and (2) explain the pseudo first order and and pseudo second order kinetics of adsorption respectively.

$\log \left(q_{e}-q_{t}\right)=\log q_{e}-K_{a d} t / 2.303$

The $\mathrm{q}_{\mathrm{e}}$ is the mass of metal adsorbed at equilibrium $(\mathrm{mg} / \mathrm{g}), \mathrm{q}_{\mathrm{t}}$ is mass of metal adsorbed at time $t(\mathrm{mg} / \mathrm{g})$ and $\mathrm{K}_{\mathrm{ad}}$ is the first order reaction constant $(\mathrm{L} / \mathrm{min})$. The pseudofirst order considers the rate of occupation of adsorption sites to be proportional to the number of unoccupied sites. A straight line of $\log \left(\mathrm{q}_{\mathrm{e}}-\mathrm{q}_{\mathrm{t}}\right)$ verses $\mathrm{t}$ indicates the application of the first order kinetic model as shown in Figure 9.

On the other hand, equilibrium capacity may also be expressed by pseudo-second order equation as follows,

$$
\frac{t}{q_{t}}=\frac{1}{K_{2, a d} q_{e}^{2}}+\frac{t}{q_{e}}
$$

Where, $\mathrm{K}_{2, \text { ad }}$ is the second order reaction rate equilibrium constant $(\mathrm{g} / \mathrm{mg} / \mathrm{min})$. A plot of $t / q_{t}$ verses $t$ give a linear relationship for the applicability of the second order kinetic represented in Figure 10.

The amount of $\mathrm{Cr}(\mathrm{VI})$ adsorbed by the An-DVB polyHIPE calculated experimentally i.e., 0.06 $\mathrm{mg} / \mathrm{g}$ is in well accordance with the theoreticall value obtained by the pseudo second order model fitting of the data i.e. $0.061 \mathrm{mg} / \mathrm{g}\left(\mathrm{R}^{2}=0.96\right)$. Thus it is attributed that adsorption follows very well the pseudo second order adsorption kinetics.

Namasivayam et al., investigated the mechanism of adsorption process by applying the intra-particle diffusion kinetic model [39] and result is shown in Figure 11.

$q=k_{i} t^{1 / 2}+C$ 
Figure 9. Pseudo-first order kinetics

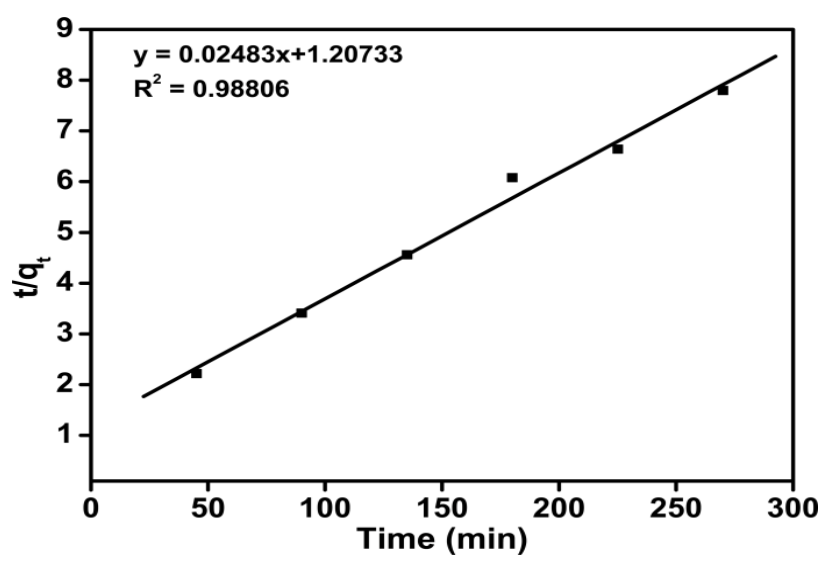

Figure 10. Pseudo-second order kinetics

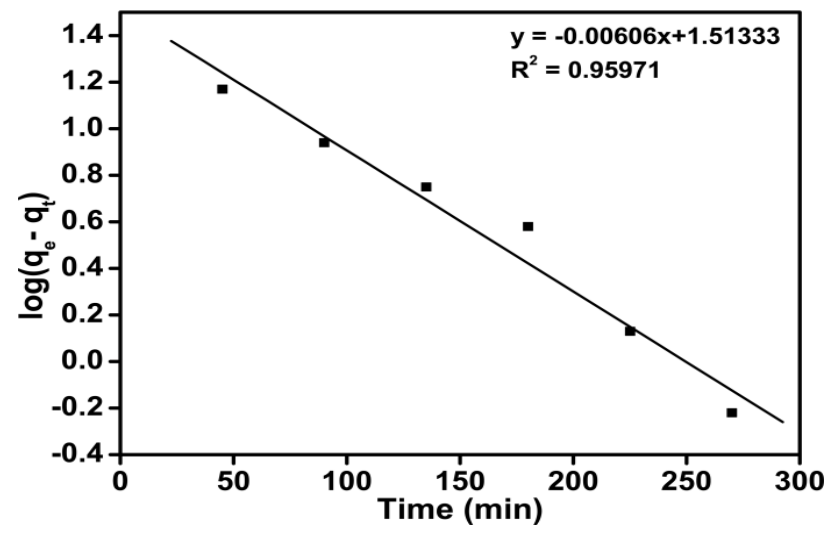

Figure 11. Intra-particle diffusion

kinetic model

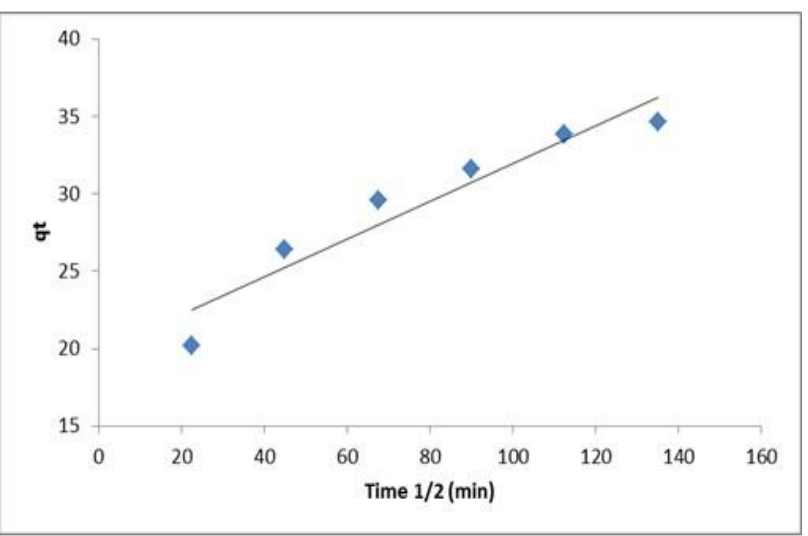

Where, $C$ is the intercept and $K_{i}$ is the intraparticle diffusion rate constant $\left(\mathrm{mg} / \mathrm{g} / \mathrm{min}^{1 / 2}\right)$. It can be evaluated from the slope of the linear plot of $q$ versus $t^{1 / 2}$. When comparing the regression coefficients, firstorder rate expression and intra-particle diffusion model was not fully valid for the present system. However, a good agreement of experimental data with the second-order kinetic model was observed.

\section{Conclusion}

The HIPE formed was polymerization of acrylonitrile and divinylbenzene using redox initiator system at $50^{\circ} \mathrm{C}$ to yield a highly 
porous polymeric monoliths. Maximum surface area of $329.74 \mathrm{~m}^{2} / \mathrm{g}$ was obtained in the case of polymer synthesized using 1:1 (monomer phase:toluene) with 1:20 (oil:water) ratio. The nitrile functionality present on the polymer backbone was post modified to amidoxime functionality and was confirmed by IR spectroscopy. The polymers synthesized using porogens were evaluated for its efficiency as a heterogeneous support for adsorption of $\mathrm{Cr}(\mathrm{VI})$ metal ion. Studies carried out at different $\mathrm{pH}$ showed that the adsorption of $\mathrm{Cr}(\mathrm{VI})$ was maximum at $\mathrm{pH}$ value of 2. Maximum adsorption efficiency of 99.8\% was found in the case of polymer synthesized using toluene as a porogen with 1:0.5 (monomer phase:toluene) ratio having 1:10 (oil:water) ratio. It was observed that the adsorption of $\mathrm{Cr}(\mathrm{VI})$ metal ions follows the pseudo second order adsorption kinetics.

\section{Acknowledgement}

We acknowledge funding from the Council of Scientific and Industrial Research (CSIR), New Delhi and Department of Science and Technology, New Delhi (Grant no. SR/SB/CE/0049/2010).

\section{References}

[1]. N. Cameron, Polymer, 2005, 46, 14391449.

[2]. K. Lissant, J. Colloid. Interf. Sci., 1966, 22, 462.

[3]. K. Lissant, B. Pearce, S. Wu, K. Mayhan, J. Colloid. Interf. Sci., 1974, 47, 416-423.

[4]. K. Lissant, K. Mayhan, J. Colloid. Interf. Sci., 1973, 42, 201-208.

[5]. K. Kim, E. Ruckenstein, Makromol. Chem. Rapid. Commun., 1988, 9, 285-290.

[6]. E. Ruckenstein, K. Kim, J. Appl. Polym. Sci., 1988, 36, 907-923.

[7]. Ruckenstein, E., Park, J., J. Polym. Sci. partC. Polym. Lett., 1988, 26, 529-536

[8]. H. Kuneida, D. Evans, N. Solans, M. Yoshida, Colloids. Surf., 1990, 47, 35-43.
[9]. H. Kuneida, N. Yano, C. Solans, Colloid. Surf., 1989, 36, 313-322.

[10]. H. Kuneida, C. Solans, N. Shida, J. Parra, Colloids. Surf., 1987, 24, 225-237.

[11]. G. Ebert, G. Platz, H. Rehange, Phys. Chem. Chem. Phys., 1988, 92, 1158-1167.

[12]. A. Barbetta, N. Cameron, S. Cooper, Chem. Comm., 2000, 3, 221-222.

[13]. S. Jerenec, M. Simic, A. Savnik, A. Podgornik, M. Kolar, M. Turnsek, P. Krajnc, Rect. Funt. Polym., 2014, 78, 32-37.

[14]. S. Kimmins, P. Wyman, N. Cameron, Rect. Fuct. Polym., 2012, 72, 947-954.

[15]. R. Owen, C. Sherborne, T. Paterson, N. Green, G. Reilly, F. Claeyssens, J. Mech. Behav. Biomed. Mater., 2016, 54, 159-172.

[16]. L. Wong, S. Barg, A. Menner, P. Pereira, G. Eda, M. Chwalla, E. Saiz, A. Bismarck, Polymer, 2014, 55, 395-402.

[17]. E. Mert, H. Yildirim, A. Uzumcu, H. Kavas, React. Funct. Polym., 2013, 73, 175-181.

[18]. P. Small, D. Sherrington, J. Chem. Soc. Chem. Commun., 1989, 1589-1591.

[19]. P. Krajnc, N. Leber, D. Stefanec, S. Kontrec, A. Podgornik, J. Chromatogr. A., 2005, 1065, 69-73.

[20]. I. Junkar, T. Krajnc, D. Nemec, A. Podgornik, A. Strancar, J. Chromatogr. A., 2007, 1144, 48-54.

[21]. H. Noorizadeh, A. Farmany, Adv. J Chem. A, 2019, 2, 128-135.

[22]. A. Ahmed, A. Ali, A. Ghazy, Adv. J Chem. A, 2019, 2, 79-93.

[23]. E. Zare, A. Motahari, M. Sillanpaa, Environmental Res., 2018, 162, 173-195.

[24]. E. Zare, M. Lakouraj, M. Masoumi, Desalination Water Treatment, 2018, 106, 209-219.

[25]. E. Zare, M. Lakouraj,A. Ramezani, New J. Chem., 2016, 40, 2521-2529.

[26]. M. Gregory, I. Sharples, M. Tucker, European Patent, 1989, 299, 762.

[27]. L. Xin, C. Hon, W. Chunua, Q. Rongjun, J. Chunnuan, S. Changmei, Z. Ying, J. Hazard. Mater., 2010, 175, 1014-1021. 
[28]. H. Egawa, T. Nonaka, K. Tsukamoto, Polymer, 1990, 22, 120-127.

[29]. T. Godjevargova, A. Simeonova, A. Dimov, J. Appl. Polym. Sci., 2001, 79, 283-288.

[30]. T. Godjevargova, A. Simeonova, A. Dimov, J. Appl. Polym. Sci., 2002, 83, 3036-3044.

[31]. C. Buchko, L. Chen, Y. Shen, D. Martin, Polymer, 1999, 40, 7397-7407.

[32]. T. Becquer, C. Quantin, M. Sicot, J. Boudot, Sci. Total Environ., 2003, 301, 251-261.

[33]. M. Wojaczynska, B. Kolarz, J. Chromatogr., 1980, 196, 75-83.

[34]. B. Kolarz, M. Wojaczynska, A. Trochimczuk, J. Luczynski, J., J. Chromatogr. A, 1986, 358, 129-135.

[35]. E. Riqueza, L. Maria, M. Aguiar, A. Aguiar, Materials Letter, 2004, 58, 502-506.

[36]. E. Riqueza, L. Maria, M. Aguiar, A. Aguiar, Polymer Bulletin, 2002, 48, 407-414

[37]. S. Lagergren, Handlingar, 1898, 24, 1-39. [38]. B. Babu, S. Gupta, Adsorption, 2008, 14, 85-92.

[39]. C. Namasivayam, K. Ranganathan, Environmental Pollution, 1993, 82, 255-261.

How to cite this manuscript: Abdul Wasif Shaikh*, Sarika Deokar, Khudbudin Mulani, Nayaku Chavan, Chelanattu Raman Rajan, Surendra Ponrathnam, Synthesis of Acrylonitrile Based High Internal Phase Emulsion Monoliths and their Application in Recovery of Heavy Metal Ions, Adv. J. Chem. A, 2020, 3(1), 36-48. 